\title{
A Group of Criterions on National Economic Security with Pass-through Model
}

\author{
Zheng Wang \\ Institute of Policy and Management, Chinese Academy \\ of Science \\ Key Laboratory of Geographic Information Science, \\ Ministry of Education East China Normal University \\ Beijing, China \\ wangzheng@casipm.ac.cn
}

\author{
$\mathrm{Min} \mathrm{Hu}$ \\ Institute of Policy and Management, Chinese Academy \\ of Science \\ Beijing, China \\ minviolin@hotmail.com
}

\begin{abstract}
The fluctuation of foreign exchange rate has a fatal influence on one country's domestic economy, foreign trade, and the relations between international economies. In this paper, I prove the Pass-through Model of Tange(1997) and propose a group of criterions of national economic security including the international trade pass-through parameter and the domestic trade pass-through parameter. By doing empirical research of Thailand, Indonesia, Korea, Japan and UK, I conclude that when the international trade pass-through parameter is far from 1 , the domestic exchange rate should be adjusted; when the domestic trade pass-through parameter is far from 0 , the fluctuation of foreign exchange rate will lead to the crisis of the domestic economy. From the results of this paper, we can see that, the exchange rate of $\mathrm{RMB}$ is relatively reasonable, and it may have a little fluctuation in the future; on the other hand, the fluctuation of exchange rate has a certain extent of influence on China's domestic market, but it can't be large.
\end{abstract}

Keywords-Exchange Rate; Pass-through Model; Financial Crisis; Historical Data

\section{INTRODUCTION}

At the end of 2007, a worldwide financial crisis erupted, and the influenced economy hasn't recovered completely. The eruption was in a sudden which remind us of a question that how to get early warnings from financial risks ${ }^{[1]}$. Because of the still existed influence of the crisis, this article chooses this crisis as the background to analyze the characteristics of the eruption of a financial crisis.

As is well-known, a financial crisis erupted in Thailand in 1997 and it spread all over the Southeast Asia soon, the currency of five countries in East Asia devalued by a large $\operatorname{margin}^{[2 \sim 3]}$. As a result of devaluation, Japan and Korean enhanced their competition of export. However, RMB remained stable then, and the countries of East Asia were the main export objects of China, so the reduction of the exports to these countries in the crisis had a great impact on China's export sector. To deal with this financial crisis, many countries adjusted their exchange rate, but they ended in different results. The devaluation of the currency of Thailand, Japan and Korean leaded to the recovery of the economy; the devaluation in Indonesia leaded to the social instability and the recession of the economy; in Russia the devaluation resulted in a serious economic crisis. In the face of the great devaluation pressure, China insisted the stable exchange rate, and didn't result in an economic crisis. We can put forward two questions: what kind of exchange rate adjustment will lead to an economic crisis; in what condition will the adjustment of exchange rate be safe?

At present many researches have been done to connect the exchange rate with financial risk. Krugman $(1986)^{[4]}$ used the theory of market pricing to explain the impact from nominal rate to the prices of imports. After the East Asia financial crisis, Xuebin Chen(1999) ${ }^{[5]}$ used the purchasing power parities theory to prove the existence of bubble in Southeast countries' exchange rates and which is the reason that lead to the eruption of the financial crisis. Razin, Rubinstein $(2005)^{[6]}$ did more researches on that the fluctuation of exchange rate would result in capital flow or impact the prices of domestic market and exports which leaded to an economic crisis. So this article tries to find some characteristics of exchange rate as the evidence of the existence of crisis risks.

Exchange rate means a currency's foreign price and if it is very unreasonable the international capital movement will inspire a crisis's eruption. In fact, the fluctuation of exchange rate is closely linked to the prices of traded goods, this connection is called exchange rate Pass-Through ${ }^{[7 \sim 9]}$. In the international economy, an unreasonable exchange rate Pass-Through will destroy the economic system. Therefore, the rationality of the Pass-Through can be a proof of the financial crisis. Feenstra, Kendall(1997) ${ }^{[10]}$ found that the unreasonable market pricing would lead to an incomplete exchange rate Pass-Through and this was the main reason to impact the purchasing power parity. Taylor $(2000)^{[11]}$ thought that export industries couldn't deliver the change of exchange rate to the export prices in a complete way when the competition pressure was strong and the price index was at a low level. Alan Sutherland $(2005)^{[12]}$ connected the exchange rate Pass-Through with social welfare and concluded that social welfare would change with the exchange rate fluctuations when the elasticity of the labor supply and the foreign producer's prices were set. Charles Engel $(2005)^{[13]}$ described the different degrees of exchange rate Pass-Through from the nominal price stickiness. Ravn, Schmitt-Grohe, Uribe(2010) ${ }^{[14]}$ concluded that fixed marginal costs would result in incomplete price transmission through relatively deep habit model. These researches show that we may get signs of crisis through exchange rate PassThrough. 


\section{THE THEORY OF EXCHANGE RATE PASS-THROUGH MODEL}

Because of different models of points of view, there are many different models of Pass-Through theory. This article' model is based on Tange's(1997)[15] research that he used his theory to analyze the export prices in Japan. Zheng Wang, Yi Gong(1999)[16] and Zheng Wang, Huanbo Zhang(2005)[16] used this model to analyze the tendency and safety of exchange rate of RMB then. Now, I will continue to use $\alpha, \beta$ from this model to analyze the exchange rate of some different countries.

In Tange's(1997) model, the exchange rate $r$ and price $p(t)$ had a relationship showed as:

$$
p_{a}(t)=p_{x}(t) / r^{\alpha}(t)
$$

$p_{a}(t)$ is the export price in foreign currency of period $\mathrm{t}$, $p_{x}(t)$ is the export price in domestic currency of period $\mathrm{t}, r$ is the exchange rate of direct quotation. I will use formula (2) to analyze the indexes and this won't affect the estimation ${ }_{\text {of }} \alpha$. I will use $c(t)$ to stand for the domestic price so that I can analyze the influence on domestic economy from international exchange rate and judge the safety of domestic economy.

Seeing from formula we can know that when $r$ is larger than 1 , if $\alpha<1$, the pass-through price is lower than the price decided by the exchange rate and the domestic currency should devaluate; if $\alpha>1$, the exchange is underestimated and the domestic currency should appreciate. To the opposite, when $r<1$, the judgment of $\alpha$ is opposite. For example, the exchange rate of GBP to USD is smaller than 1 , so when $\alpha>1$, GBP should devaluate; when $\alpha<1$, GBP should appreciate.

In the fact, the change of real exchange rate is in stages and the market has time-delay so that the change rate in exchange rate should be the weighted average of the recent several change rates. Tange(1997) used a hysteretic formula of several periods to express the pass-through formula:

$$
\ln p_{a}(t)=a_{0}+a_{1} \ln c(t)-\sum_{k=0}^{n} \alpha_{k} \ln r_{t-k}
$$

In the formula, ${ }^{a_{0}}$ is a constant, ${ }^{a_{1}}$ is the cost elasticity of the price expressed by foreign currency, $c(t)$ is the cost of period t, $\alpha_{k}$ is the flexibility of the exchange rate of the lag of coefficient in period t-k, $k$ is the lag length, $n$ is the number of lag years. Similarly, the relationship of domestic price and cost should satisfy the formula as:

$$
p_{x}(t)=B c(t) / r^{\beta}(t)
$$

Academically, the change of exchange rate won't cause the change of domestic price unless the raw materials need to be imported from foreign countries. So when $\beta=0$, the change of exchange rate won't cause the change the domestic price, and $\beta=0$ can be a criterion of judging exchange rate risk. We can also get a similar polynomial of domestic market showed as formula (4):

$$
\ln p_{d}(t)=d_{0}+d_{1} \ln c(t)-\sum_{k=0}^{n} \beta_{k} \ln r_{t-k}
$$

$p_{d}(t)$ is the domestic price in domestic currency of period t, $d_{0}$ is a constant, $d_{1}$ is the cost elasticity of domestic price, $\beta_{k}$ is the elasticity of exchange rate, it also has lag of coefficient in this formula.

In a word, we can use the sum of elasticity of different times to judge the trend of exchange rate and the economic risk. The sums can be express as $\sum_{k=0}^{n} \alpha_{k}$ and $\sum_{k=0}^{n} \beta_{k}$. The elasticity of international trade $\sum_{k=0}^{n} \alpha_{k}$ means the degree of real exchange rate deviated from the equilibrium rate of exchange. The elasticity of domestic trade $\sum_{k=0}^{n} \beta_{k}$ can reflect the degree of domestic economy affected by the change of exchange rate. $\sum \alpha$ and $\sum \beta$ are the weighted means of $\sum_{k=0}^{n} \alpha_{k} \quad \sum_{k=0}^{n} \beta_{k}$ main kinds of products to calculate the $\sum_{k=0}^{n} \alpha_{k}$ and $\sum_{k=0}^{n} \beta_{k}$ as the proof. The coefficient of weight here can be calculated according to the amount of sales or exports.

\section{EMPIRICAL RESEARCHES}

\section{A. Data sources}

In this article, we make empirical researches on China, Thailand, Indonesia, Korea, Japan, and England before and after the Asian financial crisis in 1997. Based on PassThrough theory and these six countries' number, we discuss the feasibility of the indexes suggested before.

During the Asian crisis, Thailand, Indonesia, Korea and Japan took actions of devaluation so that the export competitive could be enhanced and the economic condition could be improved. China is also a developing country of Asia, but the exchange rate was steady and wasn't affected by the crisis. England is from Europe and wasn't involved in the crisis at all. So we choose these six countries to make 
comparisons so as to analyze the right way of changing the exchange rate.

China's data are from the "China Statistical Yearbook of 2008", Thailand and Indonesia' data are from the UNSD's official website (http://unstats.un.org). Korea's data are from the Bank of Korea's website. Japan's data are from the National Statistics Office of Japan. England's data are from the European Central Bank's official website. For Korean, Japan, England and China I use the PPI to express cost and with the retail price index to express domestic price and with the export price index to express export price. The exchange rates in this article are all nominal rates in direct quotation system relative to USD. During the financial crisis in 2008, beside China, the other five countries were affected seriously. So the data of China are from 1988 to 2010, and the other's are from 1988 to 2008. The $n$ in the model is 2 . To analyze the development of economy, we are used to choose data of different years.

According to formula (2) and (4), we adopt least square method to do estimates of the degrees of Pass-Through at different periods. Zheng Wang, Yi Gong(1999) did the calculation of China's Pass-Through situation from 1988 to 1996. Zheng Wang, Huanbo Zhang(2005) did the calculation of Korean and Japan's Pass-Through situation from 1988 to 1996 . I will quote these three results directly in my results. For China, Korean, Japan and England, this article chooses five main industries to calculate, they are food, textile industry, fuel, electromechanical products and chemical products. For Thailand, the main export products are agricultural products and natural resources, so we choose rice, petroleum, corn and rubber four kinds of products. Similarly to Thailand, we choose rubber, petroleum, palm oil, core and cacao to calculate for Indonesia. There are too many numbers so here will only show the results of the six countries in table 1 to 23 .

\section{B. Experimental tests}

At first, we do some analysis of Thailand which is the origin of East Asia financial crisis. We can see $\sum \alpha$ before and after the financial crisis in table 1 and 2.

TABLE I. $\quad a_{1}$ AND $\sum_{k=0}^{n} \beta_{k}$ OF THAILAND (1988-1996)

\begin{tabular}{l|l|l}
\hline & \multicolumn{1}{|c|}{$\alpha_{1}$} & \multicolumn{1}{c}{$\sum_{k=0}^{n} \alpha_{k}$} \\
\hline Corn & & 1.4330 \\
\hline Rice & 0.6958 & 0.0137 \\
\hline Petroleum & -1.0604 & 0.0889 \\
\hline Rubber & 1.3660 & 0.0808 \\
\hline mean & 1.1866 & 0.588 \\
\hline
\end{tabular}

TABLE II. $a_{1}$ AND $\sum_{k=0}^{n} \beta_{k}$ OF THAILAND (1997-2008)

\begin{tabular}{l|l|l}
\hline & \multicolumn{1}{|c|}{$\alpha_{1}$} & \multicolumn{1}{c}{$\sum_{k=0}^{n} \alpha_{k}$} \\
\hline Corn & 0.9450 & 0.2651 \\
\hline Rice & 0.2608 & 0.4862 \\
\hline Petroleum & 1.1128 & 0.9852 \\
\hline Rubber & 1.3360 & 0.8600 \\
\hline mean & 1.1200 & 0.649 \\
\hline \multicolumn{2}{|l}{ During 1988-1996, the weighted mean of $\sum_{k=0}^{n} \alpha_{k}$ is }
\end{tabular}
0.588 which is much smaller than 1 . During 1997-2008, it is 0.649 which is larger. According to the model, Thailand was faced with the pressure of devaluation during 1998-1996 and this situation improved after 1997. It is consistent with the historical facts. In 1997, Thailand took actions of devaluation and improved the economy after that. Along with devaluation, however, the economy order became confused.

In table 3 and 4 , we can see whether $\sum \beta$ is consistent with the facts or not.

\begin{tabular}{|c|c|c|}
\hline TABLE III. & $d_{1} \mathrm{AND}_{k=0}$ & ILAND (1988-1996) \\
\hline & $d_{1}$ & $\sum_{k=0} \beta_{k}$ \\
\hline Corn & 1.6193 & 0.9908 \\
\hline Rice & 0.0260 & -0.722 \\
\hline Petroleum & 0.8036 & 5.843 \\
\hline Rubber & 1.413 & -0.018 \\
\hline mean & 0.966 & 1.536 \\
\hline
\end{tabular}

TABLE IV. $\quad d_{1}$ AND $^{n} \sum^{n} \beta_{k}$ OF THAILAND (1997-2008)

\begin{tabular}{|c|c|c|}
\hline & $d_{1}$ & $\sum_{k=0}^{n} \beta$ \\
\hline Corn & -0.333 & -0.328 \\
\hline Rice & -0.365 & -0.235 \\
\hline Petroleum & 0.8738 & 0.0161 \\
\hline Rubber & 1.5412 & -0.114 \\
\hline mean & 0.429 & 0.1664 \\
\hline
\end{tabular}

In table 3 , the weighted of $\sum_{k=0}^{n} \beta_{k}$ in 1988-1996 is 1.536 , which is far from 0 . According to the model, this means the change of exchange rate will arouse the instability of economy. Actually, the change of exchange rate caused the economic crisis then. During 1997-2008, the number is 0.1664 , which is much closer to 0 . In fact, the economy of Thailand was much better after 1997, which is consistent with the model. 
Another typical case is Indonesia. We can see $\sum_{k=0}^{n} \alpha_{k}$ in table 5 and 6 of Indonesia.

TABLE V. $\quad a_{1}$ AND $\sum_{k=0}^{n} \alpha_{k}$ OF INDONESIA (1988-1996)

\begin{tabular}{l|l|l}
\hline & \multicolumn{1}{|c|}{$\alpha_{1}$} & $\sum_{k=0}^{n} \alpha_{k}$ \\
\hline Rubber & 0.7557 & 0.7463 \\
\hline Petroleum & 0.3401 & 0.0692 \\
\hline Palm oil & 0.3708 & 1.0695 \\
\hline Corn & 0.7350 & 0.7580 \\
\hline Cacao & 0.4797 & 0.1190 \\
\hline mean & 0.5437 & 0.6407 \\
\hline
\end{tabular}

TABLE VI.

$$
a_{1} \text { AND } \sum_{k=0}^{n} \alpha_{k} \text { OF INDONESIA (1997-2008) }
$$

\begin{tabular}{l|l|l}
\hline & $a_{1}$ & $\sum_{k=0}^{n} \alpha_{k}$ \\
\hline Rubber & 0.3486 & 0.5339 \\
\hline Petroleum & 1.0463 & 1.0141 \\
\hline Palm oil & 1.4776 & 0.8294 \\
\hline Corn & 0.2735 & 1.3125 \\
\hline Cacao & 1.3780 & 1.4495 \\
\hline mean & 0.9042 & 0.9831 \\
\hline
\end{tabular}

In table $5, \sum \alpha$ of $1988-1996$ is 0.6407 which is much smaller than 1. It is 0.9831 in 1997-2008 which is much better than 0.6407. In fact, after the devaluation of Indonesia in 1997, its economy had been improved.

As is well-known, after the devaluation, Indonesia's economy was confused and caused political disturbance and a revolution. Can we get the same conclusion from $\sum \beta$ of Indonesia? This is shown in table 7 and 8.

TABLE VII. $\quad d_{1}$ AND $\sum_{k=0}^{n} \beta_{k}$ OF INDONESIA (1988-1996)

\begin{tabular}{l|l|l}
\hline & \multicolumn{1}{|c|}{$d_{1}$} & $\sum_{k=0}^{n} \beta_{k}$ \\
\hline Rubber & 1.1374 & 0.932 \\
\hline Petroleum & -0.078 & 1.8577 \\
\hline Palm oil & 0.3485 & 0.6189 \\
\hline Corn & 0.638 & 0.6863 \\
\hline Cacao & 2.1667 & 1.0099 \\
\hline mean & 0.8161 & 0.9404 \\
\hline
\end{tabular}

TABLE VIII. $\quad d_{1}$ AND $\sum_{k=0}^{n} \beta_{k}$ OF INDONESIA (1997-2008)

\begin{tabular}{l|l|l}
\hline & \multicolumn{1}{|c|}{$d_{1}$} & $\sum_{k=0}^{n} \beta_{k}$ \\
\hline Rubber & 0.6078 & 0.5053 \\
\hline Petroleum & 1.9697 & 1.5488 \\
\hline Palm oil & 1.2678 & -0.454 \\
\hline Corn & 1.8814 & 0.5026 \\
\hline
\end{tabular}

\begin{tabular}{l|l|l}
\hline Cacao & 1.6848 & 1.1737 \\
\hline mean & 1.4046 & 0.4988 \\
\hline
\end{tabular}

We can see that $\sum \beta$ of $1988-1996$ is 0.9404 which is far from 0 , so the domestic economy is sensitive to exchange rate. It is 0.4988 in 1977-2008 means the situation had been improved after 1997. Actually, the model is consistent with the real situation, which makes it forward to prove the rationality of the model.

Then we will analyze the situations of Korean and Japan which were also affected by the crisis in 1997. In table 9 and 10, we can see $\sum \alpha$ of Korean before and after 1997.

TABLE IX. $\quad a_{1} \operatorname{AND} \sum_{k=0}^{n} \alpha_{k}$ OF KOREAN (1988-1996)

\begin{tabular}{l|l|l}
\hline & $a_{1}$ & $\sum_{k=0}^{n} \alpha_{k}$ \\
\hline Food & & 0.647 \\
\hline Textile & 0.405 & 1.085 \\
\hline Fuel & 0.447 & 0.693 \\
\hline Elec. products & 0.611 & 0.522 \\
\hline Chemical products & 0.319 & 1.382 \\
\hline mean & 0.806 & 0.852 \\
\hline
\end{tabular}

TABLE X. $\quad a_{1}$ AND $\sum_{k=0}^{n} \alpha_{k}$ OF KOREAN (1997-2008)

\begin{tabular}{l|l|l}
\hline & $a_{1}$ & $\sum_{k=0}^{n} \alpha_{k}$ \\
\hline Food & 0.4363 & 0.751 \\
\hline Textile & 1.2887 & 1.2868 \\
\hline Fuel & 0.9469 & 1.0515 \\
\hline Elec. products & 0.7973 & 1.3761 \\
\hline Chemical products & 1.9499 & 1.4922 \\
\hline mean & 1.084 & 1.082 \\
\hline
\end{tabular}

During 1988-1996, $\sum \alpha$ is 0.852 which is smaller than 1 and is face with the pressure of devaluation. In1997-2008, it is 1.082 which is much closer to 1 and more rational.

We can see $\sum \beta$ of Korean in table 11 and 12.

TABLE XI. $\quad d_{1}$ AND $\sum_{k=0}^{n} \beta_{k}$ OF KOREAN (1988-1996)

\begin{tabular}{l|l|l}
\hline & $d_{1}$ & $\sum_{k=0}^{n} \beta_{k}$ \\
\hline Food & 1.445 & -0.79 \\
\hline Textile & 1.594 & 0.311 \\
\hline Fuel & 0.505 & -0.56 \\
\hline Elec. products & 1.265 & -0.90 \\
\hline Chemical products & 1.533 & 0.673 \\
\hline mean & 1.268 & 0.698 \\
\hline
\end{tabular}


TABLE XII.

$$
d_{1} \text { AND } \sum_{k=0}^{n} \beta_{k} \text { OF KOREAN (1997-2008) }
$$

\begin{tabular}{l|l|l}
\hline & $d_{1}$ & $\sum_{k=0}^{n} \beta_{k}$ \\
\hline Food & 1.6099 & 1.0771 \\
\hline Textile & 0.3833 & 0.7712 \\
\hline Fuel & 0.9746 & -0.273 \\
\hline Elec. products & 0.1877 & -0.431 \\
\hline Chemical products & 1.7911 & 0.1449 \\
\hline mean & 0.989 & 0.284 \\
\hline
\end{tabular}

Korean's $\sum \beta$ of $1988-1996$ is 0.698 which is much larger than 0 and this may have a big relationship with the unstable economy in Korean then. After the crisis, the economy of Korean was adjusted and the situation was better. $\sum \beta$ of $1997-2008$ is 0.284 which is much closer to 0 , and is consistent with the fact.

Similarly, Japan went through an unstable economy in 1997. Japan was affected by the crisis and the currency devaluated which, however, didn't cause the fluctuation of the economy. Then we can see $\sum \alpha$ of Japan in table 13 and 14.

TABLE XIII. $\quad a_{1}$ AND $\sum_{k=0}^{n} \alpha_{k}$ OF JAPAN (1988-1996)

\begin{tabular}{l|l|l}
\hline & $a_{1}$ & $\sum_{k=0}^{n} \alpha_{k}$ \\
\hline Food & 1.584 & 0.638 \\
\hline Textile & 1.535 & 0.608 \\
\hline Fuel & 0.789 & 0.783 \\
\hline Elec. products & 0.956 & 0.611 \\
\hline Chemical products & 0.829 & 0.442 \\
\hline mean & 1.14 & 0.588 \\
\hline
\end{tabular}

TABLE XIV. $\quad a_{1}$ AND $\sum_{k=0}^{n} \alpha_{k}$ OF JAPAN (1997-2008)

\begin{tabular}{l|l|l}
\hline & $a_{1}$ & $\sum_{k=0}^{n} \alpha_{k}$ \\
\hline Food & 1.4811 & 0.817 \\
\hline Textile & 0.0754 & 1.113 \\
\hline Fuel & -0.142 & 0.836 \\
\hline Elec. products & 0.8026 & 0.148 \\
\hline Chemical products & 0.9275 & 0.584 \\
\hline mean & 0.629 & 0.700 \\
\hline
\end{tabular}

We can find that $\sum \alpha$ of $1988-1996$ is 0.588 means that Japan may have a big pressure of devaluation. It is 0.70 in 1997-2008 which is much better. It is known to all that, because of the large pressure from America, during 1980 to 1990, JPY persist in appreciation. As a result, JPY was in the face of devaluation, and after the devaluation, the economy of Japan became much better. To analyze the domestic economy, we should see $\sum \beta$ of Japan in table 15 and 16.

TABLE XV. $\quad d_{1}$ AND $\sum_{k=0}^{n} \beta_{k}$ OF JAPAN (1988-1996)

\begin{tabular}{l|l|l}
\hline & $d_{1}$ & $\sum_{k=0}^{n} \beta_{k}$ \\
\hline Food & 0.333 & 0.055 \\
\hline Textile & 0.485 & 0.047 \\
\hline Fuel & 0.546 & 0.055 \\
\hline Elec. products & 0.841 & 0.167 \\
\hline Chemical products & 0.783 & 0.034 \\
\hline mean & 0.598 & 0.112 \\
\hline
\end{tabular}

TABLE XVI. $\quad d_{1}$ AND $\sum_{k=0}^{n} \beta_{k}$ OF JAPAN (1997-2008)

\begin{tabular}{l|l|l}
\hline & $d_{1}$ & $\sum_{k=0}^{n} \beta_{k}$ \\
\hline Food & 0.076 & -0.048 \\
\hline Textile & 0.5302 & 0.370 \\
\hline Fuel & 0.8262 & -1.053 \\
\hline Elec. products & 0.3625 & 0.166 \\
\hline Chemical products & 0.4158 & 0.167 \\
\hline mean & 0.442 & 0.041 \\
\hline
\end{tabular}

$\sum \beta$ is 0.112 in 1988-1996 and 0.041 in 1997-2008.

Both of them are close to 0 which means the domestic economy of Japan can stay steady when the exchange rate changes and the ability of dealing with crisis is strong. Actually, Japan adjusted the exchange rate in 1997 and didn't cause a domestic crisis. This is the same to the model.

To do more research of the model, we choose England where wasn't influenced by the crisis in 1997 to do some comparison. In table 17 and 18 we can see $\sum \alpha$ of England before and after 1997.

TABLE XVII. $\quad a_{1}$ AND $\sum_{k=0}^{n} \alpha_{k}$ OF ENGLAND (1988-1996)

\begin{tabular}{l|l|l}
\hline & $a_{1}$ & $\sum_{k=0}^{n} \alpha_{k}$ \\
\hline Food & 1.6339 & 0.8099 \\
\hline Textile & 1.0869 & 0.8152 \\
\hline Fuel & 1.1038 & 0.7272 \\
\hline Elec. products & 1.2652 & 0.8945 \\
\hline Chemical products & 1.1657 & 1.1545 \\
\hline mean & 1.251 & 0.915 \\
\hline
\end{tabular}


TABLE XVIII.

$$
a_{1} \operatorname{AND} \sum_{k=0}^{n} \alpha_{k} \text { OF ENGLAND (1997-2008) }
$$

\begin{tabular}{l|l|l}
\hline & $a_{1}$ & $\sum_{k=0}^{n} \alpha_{k}$ \\
\hline Food & 1.7159 & 0.5853 \\
\hline Textile & 1.0813 & 1.1261 \\
\hline Fuel & 0.595 & 0.38 \\
\hline Elec. products & 1.8583 & 1.6353 \\
\hline Chemical products & 2.8668 & 1.0034 \\
\hline mean & 1.623 & 1.057 \\
\hline
\end{tabular}

We can find that $\sum \alpha$ of England in both periods are 0.915 and 1.057 . They are both very close to 1 . Opposite to the other countries, 0.915 means that England may have a little pressure of appreciation and 1.057 means that England may have a little pressure of devaluation. In short, England has a stable exchange rate in the model which is consistent with the fact.

We can analyze the domestic situation of England in table 19 and 20.

TABLE XIX.

$$
d_{1} \operatorname{AND} \sum_{k=0}^{n} \beta_{k}
$$

\begin{tabular}{l|l|l}
\hline & $d_{1}$ & $\sum_{k=0}^{n} \beta_{k}$ \\
\hline Food & 0.9906 & -0.058 \\
\hline Textile & 0.3477 & 0.1822 \\
\hline Fuel & 1.5733 & 0.4665 \\
\hline Elec. products & 0.5828 & -0.379 \\
\hline Chemical products & 0.1983 & -0.031 \\
\hline mean & 0.739 & 0.036 \\
\hline
\end{tabular}

TABLE XX

$$
d_{1} \operatorname{AND} \sum_{k=0}^{n} \beta_{k} \text { OF ENGLAND (1997-2008) }
$$

\begin{tabular}{l|l|l}
\hline & $d_{1}$ & $\sum_{k=0}^{n} \beta_{k}$ \\
\hline Food & 1.2915 & -0.059 \\
\hline Textile & 0.1277 & 0.0838 \\
\hline Fuel & 3.3304 & 0.0049 \\
\hline Elec. products & 0.2798 & 0.0415 \\
\hline Chemical products & 0.3983 & 0.0683 \\
\hline mean & 1.086 & 0.0028 \\
\hline
\end{tabular}

$\sum \beta$ of England are 0.036 and 0.0028 of England in

both periods. They are both very close to 0 which means that England's domestic economy can stay steady from the change of exchange rate. Actually, until 2008, the development of England's economy had been stable.

Collecting the results of the above five countries, we can get table 21:

TABLE XXI. $\quad \sum \alpha$ AND $\sum \beta$ OF THE ABOVE FIVE COUNTRIES

\begin{tabular}{l|c|c|c|r}
\hline \multirow{2}{*}{ Index } & \multicolumn{2}{|c|}{ The Elasticity of International Trade $\sum \alpha$} & \multicolumn{2}{c}{ The Elasticity of Domestic Trade $\sum \beta$} \\
\hline & $1988-1996$ & $1997-2008$ & $1988-1996$ & $1997-2008$ \\
\hline Thailand & 0.588 & 0.649 & 1.536 & 0.166 \\
\hline Indonesia & 0.641 & 0.983 & 0.940 & 0.499 \\
\hline Korean & 0.582 & 1.082 & 0.698 & 0.284 \\
\hline Japan & 0.588 & 0.7 & 0.076 & -0.079 \\
\hline England & 0.915 & 1.057 & 0.041 \\
\hline
\end{tabular}

From the analysis of the five countries, we can get the conclusion that this model is rational. So we can use this model to analyze the rationality of China's exchange rate.

\section{THE EXCHANGE RATE OF RMB}

Zheng Wang, Yi Gong(1999), Zheng Wang, Huanbo Zhang(2005) did some analysis of exchange rate of RMB. And they got $\sum \alpha, \sum \beta$ of China in 1988-1996 which were $0.921,0.545$ and in 1997-2003 which were 1.928, 0.286. We can see that $\sum \alpha$ of $1988-1996$ was very close to 1 which was much better than Thailand, Indonesia and Japan, so China didn't need to follow theirs examples. As $\sum \beta$ was 0.545 and was far from 0 which meant that China's domestic economy may fall into confusion when RMB devaluated. In fact, China kept a steady exchange rate then and kept a steady economy as a result. In 2004, China was in face of change of exchange rate again. We can see from the results that $\sum \alpha$ was much bigger than 1 and $\sum \beta$ fell down from 0.545 to 0.286 which meant that RMB should appreciate and it wouldn't have a large influence on domestic economy. Actually, RMB had been in appreciation since 2005 and China's economy went into a high speed growth period.

Aiming at the present development of China, we calculated the situation of 1997-2010. And table 22 and 23 show $\sum \alpha$ and $\sum \beta$ of China. 
TABLE XXII. $\quad a_{1}$ AND $\sum_{k=0}^{n} \alpha_{k}$ OF CHINA (1997-2010)

\begin{tabular}{l|c|c}
\hline & \multicolumn{1}{|l|}{$a_{1}$} & $\sum_{k=0}^{n} \alpha_{k}$ \\
\hline Food & 0.7945 & 1.0011 \\
\hline Textile & 0.0731 & 1.3946 \\
\hline Fuel & 0.5883 & 1.2983 \\
\hline Elec. products & 0.3394 & 0.7927 \\
\hline Chemical products & 1.6698 & 0.5804 \\
\hline mean & 0.693 & 1.093 \\
\hline
\end{tabular}

TABLE XXIII. $\quad d_{1} \mathrm{AND} \sum_{k=0}^{n} \beta_{k}$ OF CHINA (1997-2010)

\begin{tabular}{l|l|l}
\hline & $d_{1}$ & $\sum_{k=0}^{n} \beta_{k}$ \\
\hline Food & 0.2037 & 0.2198 \\
\hline Textile & 0.2236 & 0.0221 \\
\hline Fuel & 0.3132 & 0.0181 \\
\hline Elec. products & 0.0198 & 0.0071 \\
\hline Chemical products & 0.3035 & 0.3494 \\
\hline mean & 0.213 & 0.142 \\
\hline
\end{tabular}

We can see from the result that $\sum \alpha$ is 1.093 and $\sum \beta$ is 0.142 which means that RMB's exchange rate has been more and more rational. As 1.093 is very close to 1 , so RMB won't stay in appreciation but come into a stage of fluctuation. As 0.142 is very close to 0 , we can find that when exchange rate changes the price of Food and Textile may increase and others will stay steady.

Seeing from table 22, $\sum_{k=0}^{n} \alpha_{k}$ of Food, Textile and Fuel are 1.011, 1.3946 and 1.2983 which are bigger than 1. As these industries of China are labor intensive industries and the cost of labors is high so that these products' price are high. What's more, along with the development of technology, we can do some deeper processing than before. As Electromechanical products of Electromechanical products and Chemical products are 0.7927 and 0.5804 which means that these two industries has been developed at a high speed and get a high level so that the competition has been improved obviously. However, as China's enterprises are still dependent on "low prices can get competitive advantage", so $\sum \alpha$ is still bigger than 1 .

Summering in table 24 we can see that exchange rate of RMB has been more and more rational and steady.

TABLE XXIV. $\quad \sum \alpha$ AND $\sum \beta$ OF CHINA

\begin{tabular}{c|c}
\hline Index & The Elasticity of International Tra \\
\hline $1988-1996$ & 0.921 \\
\hline $1997-2003$ & 1.928 \\
\hline $1997-2010$ & 1.093 \\
\hline As $\sum \beta$ is 0.142 which is still a little bigger than 0
\end{tabular}

means that the domestic market can still be influenced by exchange rate. But it is much better than 0.545 of 1997. So some kind of appreciation will stabilize the economy.

\section{SUMmaries AND POLICY SUGGestions}

Based on Tange(1997)'s model, this article comes up with the elasticity of trade $\sum \alpha, \sum \beta$ as the indexes of judging the rationality of exchange rate. By comparing the results of Thailand, Indonesia, Korean, Japan and England, this article shows the rationality of $\sum \alpha, \sum \beta$ as indexes. When $\sum \alpha$ is far from 1 , the exchange rate should be adjusted; when $\sum \beta$ is far from 0 , the change of exchange rate will lead to the eruption of economic crisis.

The results of China show that the exchange rate of RMB has been rational. As 1.093 is very close to 1 which means that the price of China's products is just a little lower than the price decided by purchasing power parity. In a long term, this situation does nothing good at capital accumulation so RMB should appreciate in a small extent. On the other hand, 0.142 is just a little bigger than 0 which means the change of exchange rate will have a little influence on the domestic market. But it has been much better than before.

To the government of China, they should insist the policy that the exchange rate of RMB should be kept in a relatively steady situation and appreciate slowly and gradually in a long term in the future. What' more, taking control of the favorable balance of trade is another important policy should be taken, such as adjusting the tariff, enhancing the labor cost properly. I think this is a correct direction of the development of RMB.

\section{REFERENCES}

[1] Hellwig, M, 2009, Systemic risk in the financial sector, De Economist, 157:129-207

[2] Andrew Berg and Catherine Pattillo. What Caused the Asian Crises: An Early Warning System Approach[J]. Economic Notes, v01. 28, No.3, November, 1999. 285 334.

[3] Liang Yuanling. The Form of Bubble Economy and the Impact of Thailand [J]. Around Southeast Asia. 1999, 1, 53 57

[4] Paul Krugman. Pricing to market when the exchange rate changes. NBER working paper. 1986 No. 1926.

[5] Chen Xuebin. Analyzing the Recent Change Tendency of RMB Exchange Rate[J]. Economic Research.1999;1. 
[6] Assaf Razin, Yona Rubinstein. Evaluation of Exchange-Rate, Capital Market, and Dollarization Regimes in the Presence of Sudden Stops . NBER Working Paper No. 11131. 2005(2).

[7] Ohno K. Export pricing behavior of manufacturing: A.U.S.-Japan comparison[J]. IMF Staff Papers, 1989;36(3):551 579.

[8] Khosla A. Exchange rate pass-through and export pricing from the Japanese economy[J]. the Japanese and International Economies, 1991;5:41 59

[9] Marston R C. Pricing to market in Japanese rate[J]. Faderal Reserve Bulletin, 1991;72(6):366 379.

[10] Feenstra, Robert C., Jon D. Kendall. Pass-through of Exchange Rates and Purchasing Power Parity[J]. Journal of International Economics. 1997, 43. 237 261.

[11] Taylor, John B. Low Inflation, Pass-Through, and the Pricing Power of Firms[J]. European Economic Review. 44. 2000. pp. 1389 1408
[12] Alan Sutherland. Incomplete Pass-Through and the Welfare Effects of Exchange Rate Variability[J]. Journal of International Economics. 65(2005). 375 399.

[13] Charles Engel, 2005, Equivalence Results for Optimal Pass-Through, Optimal Indexing to Exchange Rate and Optimal Choice of Currency for Export Pricing. NBER working paper, No. 11209.

[14] Morten O. Ravn, Stephanie Schmitt-Grohe, Martin Uribe. Incomplete Cost Pass-Through under Deep Habits[J]. Review of Economic Dynamics. 13(2010). 317 332.

[15] Tange T. Exchange rates and export price of Japanese manufacturing[J]. Journal for policy Modeling, 1997; 10(2): 195 206.

[16] Wang Zheng, Gong Yi, Wang Jinra. Analyzing the Problem of RMB Exchange Rate Form the Pass-through Theory of Trade [J]. Journal of management sciences in China. 1999, 2(3): 85 91

[17] Wang Zheng, Zhang Huanbo. Exchange Rate and Economic Crisis: Aanlyzing the problem of RMB Exchange Rate [J].Economic Science. 2005, 5, 72 79. 